\title{
Rotavirus-Impfung ab sechs Wochen: Das gilt auch für Frühchen!
}

- Das Zeitfenster für die erste RV-Impfung ist begrenzt: Säuglinge sollten zwischen der sechsten und zwölften Lebenswoche die erste Dosis der Vakzine erhalten. Doch gilt diese Empfehlung auch für Frühgeborene?

Prof. Dr. Hans-Iko Huppertz, Bremen, bejahte diese Frage: Beide verfügbaren Impfstoffe können nach dem chronologischen Alter, also unabhängig vom Gestationsalter sechs Wochen nach der Geburt, gegeben werden. Auch die STIKO empfiehlt generell die Impfung Frühgeborener entsprechend dem chronologischen Alter.

Allerdings sind laut Huppertz zwei Punkte zu berücksichtigen: Erstens wird das Impfvirus möglicherweise ausgeschieden und daher zögern die Kliniken, die Kinder während des stationären Aufenthaltes zu impfen. Mit der Entlassung ist die Impfung dann problemlos durchzuführen. Zweitens sollten sehr kleine Frühgeborene nach der Impfung zwei bis drei Tage klinisch über-

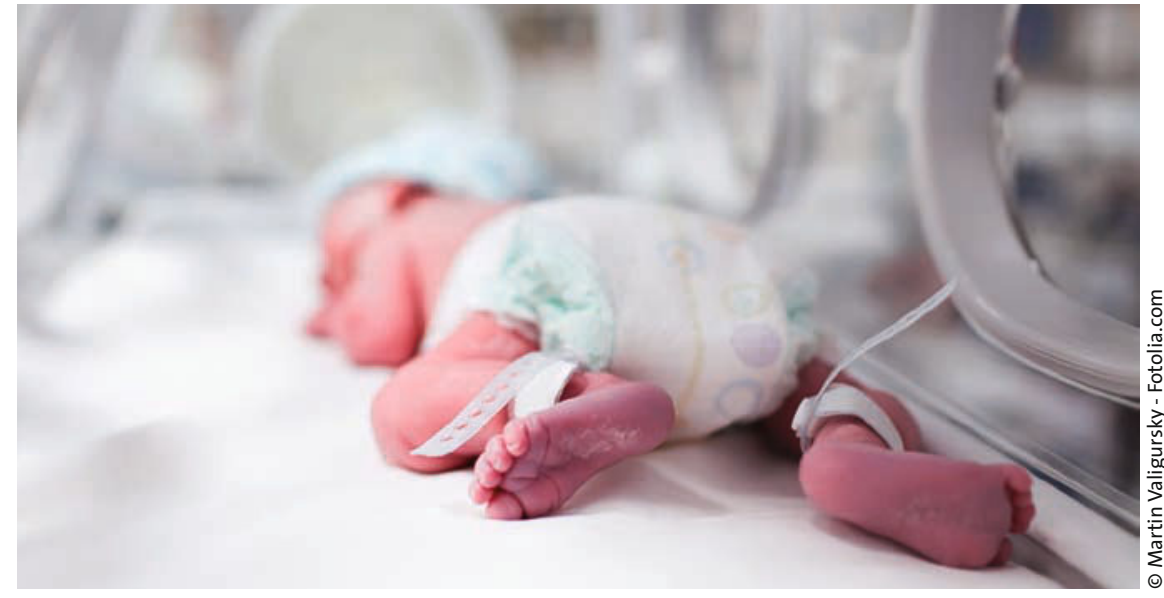

wacht werden, entsprechend dem Vorgehen bei der konventionellen 6-fach- und der Pneumokokkenkonjugat-Impfung. Zudem empfahl Huppertz, bei diesen extremen, vor der 28. Woche geborenen Frühchen mit der ersten Impfdosis etwas länger als sechs Wochen, eventuell bis zur Entlassung, zu warten. So gebe man den Kindern Zeit, zunächst einmal mit möglichen anderen Problemen fertig zu werden.

H.-I. Huppertz. Rotavirusimpfung - was gibt es Neues

\section{Die $\mathrm{H}_{1} \mathrm{~N}_{1}-$ Pandemie - ein panischer Probelauf}

_ Prof. Dr. Markus Knuf, Mainz, erinnerte sich: „Irgendwann war es dann soweit, dass die Vor-und Nachteile der verschiedenen Adjuvanzien bei Aldi an der Kasse diskutiert wurden. "War das erste Halbjahr 2009 noch davon gekennzeichnet, dass angesichts der von Nordamerika nach Europa vordringenden neuen Reassortante des $\mathrm{A} / \mathrm{H}_{1} \mathrm{~N}_{1}$ Influenzavirus schnellstmöglich ein Impfstoff gefordert wurde, so schlug die Stimmung im Spätsommer um: Die Angst vor den Nebenwirkungen der dann erhältlichen Vakzinen war größer als vor der überraschend milde verlaufenden Grippewelle. Von den für Deutschland bestellten 34 Mil-

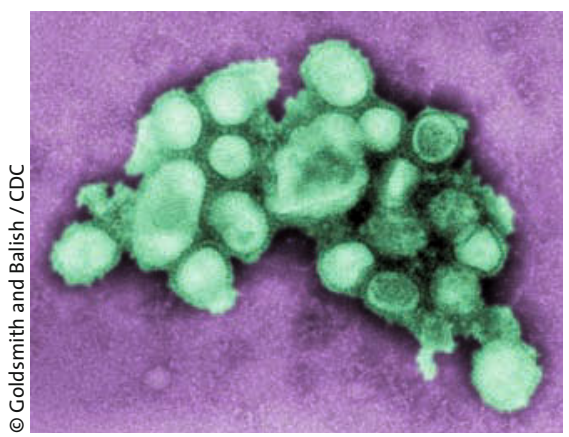

lionen Impfdosen wurden letztlich 27 Millionen nicht verwendet.

Der Umgang mit der $\mathrm{H}_{1} \mathrm{~N}_{1}$-Pandemie in Deutschland wird im Rückblick oft als Desaster gesehen - zu Unrecht, konterte Prof. Dr. Hans-Iko Huppertz, Bremen. Vieles sei erstaunlich gut gelaufen: Nur durch eine hervorragende Zusammenarbeit im wissenschaftlichen Bereich war es überhaupt möglich, innerhalb von sechs Monaten einen Impfstoff bereitzustellen. Die im internationalen Vergleich späte und milde autochthone Influenzawelle in Deutschland zusammen mit der insgesamt geringen Mortalität könnten ebenfalls als Hinweise gesehen werden, dass das öffentliche Gesundheitswesen doch einiges richtig gemacht hat. Die Bevorratung mit dem Impfstoff sei vor diesem Hintergrund mit der Anschaffung eines Feuerwehrautos vergleichbar, erklärte Huppertz. Auch hier hoffe man, dass der Einsatz gar nicht nötig wird. Als klarer Fehler der Behörden bleibt dagegen festzuhalten: die geheim gehaltenen Verträge mit den Impfstoffherstellern, die Bestellung unterschiedlicher Vakzinen für Beamten und Bevölkerung, die unklaren Impfempfehlungen und die unflexiblen Bestellmöglichkeiten. Dazu kommt insgesamt die unprofessionelle und widersprüchliche Kommunikationspolitik.

Das Fazit der Referenten: Die Gefahr einer $\mathrm{H}_{1} \mathrm{~N}_{1}$-Pandemie mit hoher Mortalität ähnlich der Spanischen Grippe 1918/19 sei real gewesen. Nur eine oder zwei Mutationen an den richtigen Stellen hätten die Infektiosität und Letalität des Virus entscheidend verändern können.,,Wir haben Glück gehabt, dass die Pandemie relativ harmlos verlaufen ist“, hielt Knuf fest. Insofern kann man das letzte Jahr als Probelauf für eine potenzielle gefährlichere Pandemie der Zukunft werten. Für die kommende Influenzasaison 2010/2011 ist das $\mathrm{H}_{1} \mathrm{~N}_{1}$ Virus übrigens in die gewohnten saisonalen Impfstoffe integriert, insofern ist eine gesonderte Impfung nicht mehr sinnvoll.

es

Huppertz H-I. Klinik, Diagnose und Therapie der neuen Influenza $\mathrm{A} / \mathrm{H}_{1} \mathrm{~N}_{1}$. Knuf $\mathbf{M}$. Impfung gegen die neue Influenza $\mathrm{A} / \mathrm{H}_{1} \mathrm{~N}_{1}$ 